\title{
An Estimated Search and Matching Model of the Croatian Labor Market: Post-crisis Analysis
}

\section{Jelena Rkman}

Osaka University, Graduate School of Economics, Osaka, Japan jelenarkman@gmail.com
CroEconSur

Vol. 22

No. 2

December 2020

pp. $35-72$

Received: March 12, 2020

Accepted: October 26, 2020

Research Article

doi:10.15179/ces.22.2.2

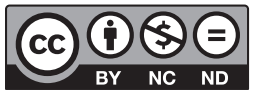

\section{Abstract}

The paper specifies a simple search and matching model of the labor market and studies how well the model can describe aggregate Croatian labor market dynamics. The model developed is a discrete-time search and matching model with convex vacancy posting costs and two types of shocks: productivity and separation shocks. The model is estimated on unemployment and vacancy data during the period from 2012 to 2020 by using Bayesian methods. The model fits the data well and the estimation shows that productivity shocks are the main driving force of the fluctuations in the labor market, especially for the case of vacancies and output, while the separation shock process accounts for a large percentage of unemployment fluctuations. 
Keywords: unemployment fluctuations, search and matching, Croatia, Bayesian estimation

JEL classification: C11, C51, E24, J64

\section{Introduction}

High unemployment rates in many European countries are causing concern not just to individuals directly affected by those figures, but also to governments and policy makers. Even though many countries have recovered from the global financial crisis, there is a large number of countries struggling to improve the situation on their labor markets. Among the EU member states, Eurostat reports that Croatia had one of the highest youth and adult unemployment rates in Europe in 2013, 49.9 percent and 14.6 percent, respectively. The situation has been improving over the years, but with potentially irreversible consequences in the form of emigration and financial losses, both on the individual and on the country level.

Labor markets are a good instrument to evaluate the performance of an economy, as by observing them we can assess sources of an existing problem such as unemployment, as well as the success of implemented policies. Unfortunately, throughout the years, the implemented labor market policies have proven not to have the desired effect in Croatia. Nevertheless, they have just been re-applied to a wider group of disadvantaged individuals, while the number of job openings has not increased (Obadić, 2003). Furthermore, the policies often do not address the issue of mismatch between educational and employment policies (Obadić \& Majić, 2013), resulting in higher unemployment of high-skilled individuals as well as emigration of such individuals. Only a small amount of research has been done to investigate the main sources of the problems of unemployment on the labor market in Croatia, with an aim to design appropriate policies and develop 
a better mechanism to test the effectiveness of implemented policies (Obadić, 2004; Obadić, 2006; Botrić, 2009).

This paper focuses on determining to what degree a simple search and matching model based on Lin and Miyamoto $(2014)^{1}$ can describe the dynamics of the Croatian labor market and provide insight on the main driving forces behind unemployment, vacancy, and output fluctuations. Search and matching models have often been used to address a variety of labor market issues, with unemployment rate differences as well as labor market comparisons being the main focuses, and thus serve as a good tool to explore the Croatian labor market. The model in this paper is a discrete-time search and matching model with two exogenous shock processes: productivity and separation shocks. The model is used as a data-generating process for the aggregate labor market variables. Parameters that describe the dynamics of the labor market are estimated by using Bayesian methods.

The results of this paper show that the productivity shock accounts for almost all vacancy fluctuations and 85 percent of output fluctuations, while the separation shock plays a minor, but important role, especially for output fluctuations. Furthermore, both productivity and separation shocks play almost equally important roles in explaining unemployment fluctuations.

The model can account for the volatility of the unemployment rate, vacancy rate, and output. Furthermore, it successfully replicates the negative relationship between unemployment and vacancies. Focusing on the shock processes, the model matches the observed volatility well, although the estimated baseline model is unable to replicate the level of correlation between the two.

The model replicates the observed behavior of the relative standard deviation of vacancies to output, as well as the relative standard deviation of unemployment to output. By changing the set of observables from unemployment and vacancies to

1 Lin and Miyamoto (2014) build on the model by Pissarides (2000) by including three exogenous time-varying shocks (separation, productivity, and markup shock) and use convex vacancy posting costs. 
vacancies and output, the performance of the model slightly diminishes, although the model is still able to perform satisfactorily.

The contribution of this paper is twofold. First, the paper adds to the literature on the issue of unemployment in Croatia. To the best of my knowledge, this is the first paper that focuses on using a standard search and matching model and Bayesian estimation to explain the aggregate labor market dynamics in Croatia, determining the main sources of unemployment, vacancy, and output fluctuations. Second, the finding of this paper that unemployment fluctuations are strongly influenced by the separation rate has important implications for policy formation. Even though the data do not include the 2008-2009 period of the financial crisis, the separation rate strongly affects the unemployment rate fluctuations, suggesting more complex underlying reasons and encouraging additional research on the effectiveness of implemented policies and labor market institutions.

The remainder of the paper is organized as follows. Section 2 reviews the relevant search and matching literature, while Section 3 focuses on understanding the existing issues on the Croatian labor market, as well as its features over the business cycle. Section 4 describes the search and matching model with convex vacancy posting costs and two exogenous shocks, while Section 5 contains the calibration and estimation of the model, and studies the quantitative performance of the model by changing the observable variables and the form of vacancy posting costs. Section 6 concludes the paper.

\section{Related Literature}

This paper is related to numerous papers on search and matching models, while being one of the first attempts to explain the unemployment dynamics of the Croatian labor market by using a Bayesian estimation of a search and matching model. 
There have been several papers that focus on exploring the issues and properties of the Croatian labor market by using search and matching models.

Both Obadić (2004) and Tomić (2014a) focus on the problem of structural unemployment, a common issue in transition economies. On one hand, Obadić (2004) focuses on exploring structural unemployment using a disaggregated analysis of a matching process on a county level and shows strong existence of regional mismatch between unemployment and vacancies in several transition countries, including Croatia. Furthermore, apart from the standard regional mismatch, the paper shows that, due to a decrease in technology matching efficiency, employment decreased as well. On the other hand, Tomić (2014a) explores the proportion of unemployment that can be attributed to structural mismatch on the labor market and shows that mismatch between unemployment and vacancies does not have a large impact on the unemployment dynamics in Croatia (range of 1 percent to 6 percent, depending on the time period) and is unable to explain the high and persistent unemployment issue in Croatia.

Another issue present on the labor market is matching efficiency - the productivity of the process of matching jobseekers to open vacancies. The issue of matching efficiency has been present on the Croatian labor market for several decades and has been a topic of research ever since. Šergo, Poropat, and Gržinić (2009) observe the Croatian labor market in the period between 1990 and 2008, verify the existence of a negatively-sloped Beveridge curve, and show that the labor market has been showing greater matching efficiency since the 1990s, indicating a positive development of the labor market. Confirming this result, Tomić (2014b) explores the efficiency of the matching process on the labor market in Croatia and shows that the matching efficiency has increased over time, but with significant variations among regions.

High inactivity and unemployment issues have been present in Croatia during the transition and post-transition period. Tomić and Domadenik (2012) focus on the problem of matching and adverse selection in a transition and post-transition 
context by expanding the model of adverse selection with firing costs to determine the main causes of high unemployment and inactivity rates. The results show the existence of adverse selection on the Croatian labor market for the unemployed.

Adding to existing literature that incorporates search and matching models to explore the Croatian labor market, the focus of this paper is on understanding the aggregate labor market dynamics in Croatia and explaining the causes of high unemployment volatility. Although the model and reasoning of this paper were inspired by Lin and Miyamoto (2014), who developed a simple discrete-time search and matching model with convex vacancy posting costs and three shock processes, the methodology used in this paper is also closely related to Lubik (2012).

Much research has been done to improve the performance of search and matching models, but it is mainly focused on developed countries, specifically the United States. Shimer (2005) stresses the inability of search and matching models to generate the observed unemployment and vacancy fluctuations in response to productivity shocks observed on the US labor market. Following Shimer's critique, extensive research has been done to improve the performance of the models (Hagedorn \& Manovskii, 2008; Hall \& Milgrom, 2008; Menzio \& Shi, 2011; Robin, 2011). In all these models, productivity shocks have a strong effect on job-to-job transition, as well as on the construction and destruction of lower productivity jobs, without assuming wage rigidity. However, most of the literature focuses on the labor markets of OECD countries, while not many studies have been conducted for developing countries or countries that have just recently gained the status of a developed country. Even though these kinds of countries are often the ones struggling the most in times of crisis, most research is done for the leading countries in the world. Due to this fact, this paper focuses on explaining the labor market dynamics in Croatia, a country that recently took a first step in joining more developed and successful countries in Europe. 


\section{Background and Data}

\subsection{Background}

After declaring independence in 1991, Croatia struggled with the transition from a socialist system to a market economy, experiencing changes toward establishing institutions and processes that support private enterprises and entrepreneurship. Throughout the 2000s, there have been persistent issues, weaknesses, and inequalities on the Croatian labor market, affecting job creation. Despite the underlying problems, the trends on the labor market improved, resulting in an increase in employment and a decrease in unemployment (Franičević, 2011).

The global financial crisis started showing effects already in mid-2008, while the deceleration of economic growth continued even further by the end of the year. In 2009, the effects of the crisis were significant, resulting in high unemployment rates and negative economic growth, persisting until 2014 (CNB, 2020). The crisis, adding to the existing issues, created new ones, negatively affecting several sectors in terms of employment and wages (Franičević, 2011). Large differences in the effects of the crisis were observed between the public and private sector, where public sector workers remained well protected in terms of wage cuts compared to private sector workers (Nikolic, Rubil, \& Tomić, 2017).

Weber (2016) argues that the poor outcomes on the Croatian labor market were not just consequences of the financial crisis, but rather that they reflect structural flaws of the labor demand, as well as the labor supply side of the market. He claims that the minimum wage in Croatia obstructs employment possibilities of young, low-skilled, and long-term unemployed workers, who are the most vulnerable to negative changes on the labor market. Furthermore, before the 2013 and 2014 reforms, the employment regulations were too strict, hindering job creation and resulting in poor labor market outcomes during the crisis and slow recovery afterwards.

Observing the labor demand side, Orsini and Ostojić (2015) show that during the crisis wages adjusted notably slower compared to EU-10 countries, 
confirming that Croatia lags behind other EU member countries in terms of wage adjustments, resulting in firms opting for employment reduction rather than wage reduction during crises, as well as being slow in hiring new workers. On the other hand, looking at labor supply, Obadić and Majić (2013) show that there has been a drastic increase in highly educated workers, satiating the labor market for high-skilled workers and indicating there is a mismatch between the education system and labor market needs. This kind of labor market distortion, which is seen as a discrepancy between labor supply and labor demand, is a serious threat to economic growth and development of the Croatian labor market, resulting in unemployment.

As mentioned previously, Croatia is a country with relatively rigid labor market legislation, and as such is more susceptible to showing signs of labor market duality. Following claims of duality of the labor market by Franičević (2011), Brkić (2015) argues that there is no clear segmentation between temporary and permanent employment, but that segmentation exists between the public and private sector, especially before the implementation of the 2013 and 2014 reforms on employment protection. The main effect of the reforms was a decrease of the employment protection index, putting it in the range of most OECD countries. When a country has stricter employment protection legislation, firms are more unwilling to hire new employees, which reduces job creation, as mentioned in Weber (2016).

Policy responses to the crisis have been slow and insufficient, focusing on shortterm measures based on budget revisions and cost cuts, almost neglecting the increasing levels of unemployment (Franičević, 2011). In general, active labor market policies (ALMPs) are regarded as the best tool to fight unemployment. Nevertheless, both government spending and the low coverage of ALMPs put Croatia in the lower half compared to other EU countries (World Bank, 2010; Tomić, Rubil, Nestić, \& Stubbs, 2019). 
During labor market turbulences, one of the most affected groups of individuals are youths, and as such are often the focus of implemented ALMPs. Tomić and Zilic (2020) evaluated vocational training for work without commencing employment, the main measure of implemented ALMPs in Croatia. The measure showed almost no effect on either employment or unemployment probability of Croatian youths, while driving a certain percentage of them into inactivity, leading the authors to conclude that the main goal of decreasing youth unemployment probability was not met.

As previous research shows, structural flaws of the Croatian labor market were amplified by the financial crisis in 2008. Joining the European Union in 2013 gave both employed and unemployed individuals the opportunity to easily seek work outside of Croatian borders. According to Eurostat, in the period between 2012 and 2017, the number of people who emigrated from Croatia almost quadrupled, while the number of immigrants increased as well, but not to the extent to counter the magnitude of emigration. This alarming fact could have dramatic consequences in the future. The situation on the Croatian labor market has improved in recent years, although it remains far from satisfactory and the labor market is in dire need of adequate policy changes.

\subsection{Data and Stylized Facts}

Due to data availability, this paper will use observations of the Croatian labor market variables from the first quarter of 2012 to the first quarter of 2020. The unemployment data are obtained from the Croatian Bureau of Statistics and are calculated using the Labor Force Survey (LFS) ${ }^{2}$, while the rest of the data are obtained from the Eurostat database. Additionally, Section 5.5.3 uses Online Vacancy Index (OVI) data obtained from the Institute of Economics, Zagreb.

2 The number of unemployed workers was slightly overestimated until 2014, when changes in the LFS were made based on ILO standards, but data remain comparable: until 2014, the sample frame based on the 2001 Census was used, and from 2014 the new sample frame was based on the data from the Census of Population, Households and Dwellings in 2011. Additionally, due to availability of new and updated estimates of the total population, there has been a data revision for 2015 and 2016 to make the LFS data harmonized with demographic data. 
OVI is a monthly index of online job advertisements developed in cooperation between the Institute of Economics, Zagreb and the online job posting portal MojPosao. More details are given in Section 5.5.3.

Data are seasonally adjusted using the X-13 ARIMA filter and the logged data are de-trended using the Hodrick-Prescott filter with smoothing parameter 1,600.

The reason for using a rather short dataset is the lack of data on all the variables needed for the estimation. Data on the vacancy rate are reported only from the beginning of 2012, while data on labor market transitions that are needed for calculating the job finding and separation rates exist from $2010 .{ }^{3}$ OVI data exist prior to 2012, but for comparability reasons the paper will use all data from the 2012-2020 period.

The aim of this section is to explain the cyclical properties of the Croatian labor market. The focus is on the behavior of seven variables: the unemployment rate $u$, the vacancy rate $v$, the job finding rate $f$, the separation rate $s$, labor productivity $A$, labor market tightness $\theta$, and output $y$. Due to a change in measurement of wages in 2015 performed by the Croatian Bureau of Statistics, the data before and after the change are not comparable and are not included in this paper.

Figure 1 shows the cyclical properties of the above-mentioned variables, while Table 1 contains business cycle statistics. The unemployment rate shows countercyclical properties, the correlation between the unemployment rate and labor productivity being -0.17 . The vacancy rate is pro-cyclical, with correlation between the vacancy rate and labor productivity amounting to 0.12 . Both series do not exhibit strong cyclical properties, but co-move negatively as the literature suggests, with correlation between the two variables being -0.3 .

Both the unemployment rate and the vacancy rate exhibit higher volatility compared to labor productivity. The unemployment rate is almost six times more volatile, while the vacancy rate is ten times more volatile than labor productivity.

3 In previous years, there had been changes in the legal obligations of employers regarding job vacancy reporting to the Croatian Employment Service, but as of 2004 the transitional effects of these changes were no longer observed and thus no issues regarding the use of the vacancy rate are noticed (CNB, 2010). 
Both the unemployment rate and the vacancy rate exhibit a rather high degree of autocorrelation, 0.72 and 0.77 , respectively.

Figure 1: Cyclical Properties of Labor Market Variables

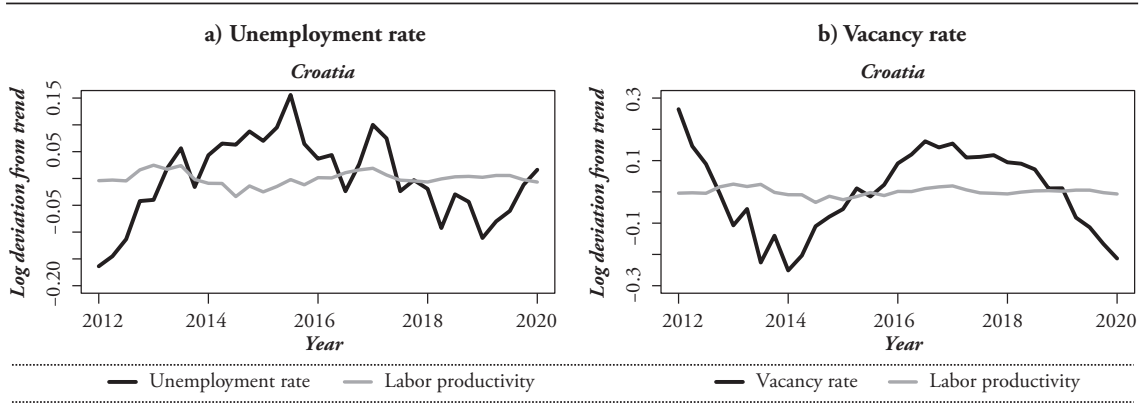

c) Job finding rate

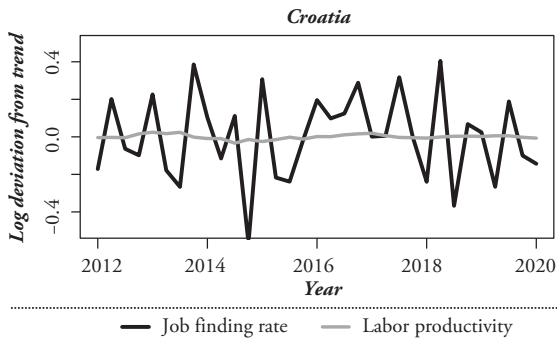

e) Labor market tightness

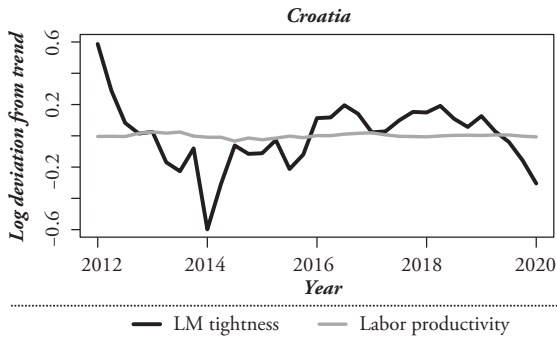

d) Job separation rate

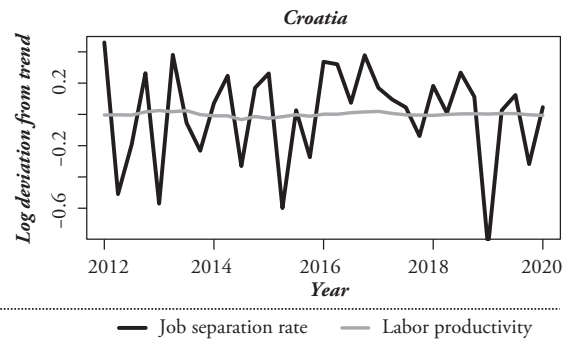

Notes: The black line represents the cyclical properties of the unemployment rate, the vacancy rate, the job finding rate, the job separation rate, labor market tightness, and output, while the gray line indicates the cyclical properties of labor productivity. Since there are notable differences in log deviations from trend between labor productivity and other variables, the scale of each graph is adjusted to show cyclical properties as clearly as possible. The sample covers the 2012Q1-2020Q1 period. All data series are reported as log deviations from the HP trend (smoothing parameter $1,600)$.

Source: Author's calculations. 
Labor market tightness is one of the central variables in search and matching models and is defined as the ratio of vacancies and unemployment. In the case of Croatia, labor market tightness is pro-cyclical, with correlation between the labor market tightness and labor productivity being 0.14 . Furthermore, both the job finding rate and job separation rate are pro-cyclical. The correlation between the job finding rate and labor productivity is slightly positive, while the correlation between the job separation rate and labor productivity is 0.15 . The separation rate and job finding rate exhibit negative autocorrelation, as well as higher volatility compared to other variables, 0.32 and 0.23 , respectively.

The output variable, which is measured as real GDP in per capita terms, shows pro-cyclical properties, with the correlation between output and labor productivity being 0.49 . Furthermore, the volatility of output is small (0.012), while it exhibits a high level of autocorrelation (0.82).

Table 1: Business Cycle Statistics

\begin{tabular}{|c|c|c|c|c|c|c|c|c|}
\hline & & & & & & & \\
\hline & & $u$ & $v$ & $f$ & $s$ & $A$ & $\theta$ & $y$ \\
\hline Standard deviation & & 0.076 & 0.132 & 0.229 & 0.316 & 0.013 & 0.209 & 0.012 \\
\hline Autocorrelation & & 0.716 & 0.774 & -0.389 & -0.266 & 0.662 & 0.550 & 0.822 \\
\hline \multirow[t]{7}{*}{ Correlation matrix } & $u$ & 1 & -0.301 & 0.209 & 0.172 & -0.173 & -0.610 & -0.802 \\
\hline & $v$ & - & 1 & 0.152 & 0.192 & 0.120 & 0.856 & 0.631 \\
\hline & $f$ & - & - & 1 & -0.126 & 0.015 & 0.166 & 0.093 \\
\hline & $s$ & - & - & - & 1 & 0.147 & 0.038 & -0.012 \\
\hline & $A$ & - & - & - & - & 1 & 0.144 & 0.495 \\
\hline & $\theta$ & - & - & - & - & - & 1 & 0.759 \\
\hline & $y$ & - & - & - & - & - & - & 1 \\
\hline
\end{tabular}

Notes: All data are seasonally adjusted using the X-13 ARIMA filter. The sample covers the 2012Q1-2020Q1 period. All data series are reported as log deviations from the HP trend (smoothing parameter 1,600).

Source: Author's calculations.

\section{The Model}

The model used is a simple discrete-time search and matching model with convex vacancy posting costs that will serve as a data-generating process for the empirical analysis in Section 5. The model is closely related to the model of Lin and 
Miyamoto (2014), which builds on the model by Pissarides (2000) with several extensions that will be discussed in the following subsections.

\subsection{The Setting}

Time is discrete and the period is one quarter. The market consists of a continuum of identical firms that employ workers by posting vacancies. The workers supply a unit of labor and produce intermediate goods. Both workers and firms are identical, risk-neutral, and infinitely lived. The size of the labor force is normalized to one.

In addition to workers and firms, there is a large number of symmetric retailers that buy intermediate goods in order to produce final goods that are sold on a monopolistic competitive market. We assume that the worker derives utility by consuming final goods, aggregated by using the Dixit-Stiglitz consumption index as in Lin and Miyamoto (2014), which is then used as a numeraire.

A worker can exist in only two states: employed or unemployed. If a worker is unemployed, he/she receives a flow utility from non-market activity and actively searches for a job. If a worker is employed, he/she earns a wage $w$ and produces output.

Firms post vacancies to employ new workers who produce goods for the firm. In every period $t$, a firm chooses its level of employment $n_{t}$ and the number of vacancies $v_{t}$ it will post. The real cost of posting vacancies is convex with the form $\frac{\kappa v_{t}^{\varphi}}{\varphi}$, where $\kappa>0$. The reasoning behind including convex vacancy posting costs instead of linear ones that are used in most of the literature, comes from the fact that the curvature of the vacancy posting costs might affect the quantitative property of the model (Fujita \& Ramey, 2007). Due to this fact, the paper includes both linear and convex vacancy posting costs, but for the baseline case, following Rotemberg (2006), convex costs are used. 
In every period, a fraction of workers and firms get separated. The literature suggests that incorporating an endogenous job separation rate, instead of an exogenous one, does not require real wage rigidities in order to solve the unemployment volatility puzzle (Fujita \& Ramey, 2012; Abeille-Becker \& Clerc, 2013). As the paper does not show large traces of the Shimer puzzle, following Lise, Seitz, and Smith (2005), instead of a constant exogenous rate, this paper will incorporate a time-varying exogenous separation rate $s_{t}$, as it has been shown to be suitable for estimation.

\subsection{Labor Market Flows and the Matching Function}

Due to search frictions, firms and workers are not matched instantaneously. The labor market matching process is time-consuming and is determined by a CobbDouglas matching function of the following form:

$m\left(u_{t}, v_{t}\right)=m_{0} u_{t}^{\alpha} v_{t}^{1-\alpha}$,

where $m_{0}>0$ is the match efficiency and $0<\alpha<1$ is the match elasticity.

Since the size of the labor force is normalized to one, the number of employed workers $n_{t}$ is defined as the difference between the size of the labor force and the number of unemployed workers $u_{t}$ :

$n_{t}=1-u_{t}$.

Inflows into unemployment exist due to an exogenous separation rate $0<s_{t}<1$, that takes place at the beginning of period $t$. The separation rate is assumed to be a stochastic first-order autoregressive process of the form:

$\log s_{t}=\left(1-\rho_{s}\right) \log s-\rho_{s} \log s_{t-1}+\epsilon_{s, t}$,

where $0<\rho_{s}<1,0<s<1$, and $\epsilon_{s, t} \sim \mathcal{N}\left(0, \sigma_{s}^{2}\right)$. 
One of the assumptions used in the model is that both the newly formed matches and old matches face the same separation rate, giving the employment evolution equation:

$n_{t}=\left(1-s_{t}\right)\left(n_{t-1}+m_{0} u_{t-1}^{\alpha} v_{t-1}^{1-\alpha}\right)$.

Labor market tightness in period $t$ is defined as $\theta_{t} \equiv v_{t} / u_{t}$. The job finding rate $p\left(\theta_{t}\right)$, which is the probability that a worker will be matched with a firm, is defined using the matching function as $p\left(\theta_{t}\right) \equiv m\left(u_{t}, v_{t}\right) / u_{t}=m_{0} \theta_{t}^{1-\alpha}$. Similarly, the job matching rate, which is the probability that a firm will be matched with a worker, is defined as $q\left(\theta_{t}\right) \equiv m\left(u_{t}, v_{t}\right) / v_{t}=m_{0} \theta_{t}^{-\alpha}$.

\subsection{Firm's Optimization}

Output $y_{t}$ of a firm is linear in employment and defined as:

$y_{t}=A_{t} n_{t}$

where $A_{t}$ is an aggregate labor productivity process that is assumed to be a stochastic first-order autoregressive process of the form:

$\log A_{t}=\left(1-\rho_{A}\right) \log A-\rho_{A} \log A_{t-1}+\epsilon_{A, t}$,

where $0<\rho_{A}<1,0<A<1$, and $\epsilon_{A, t} \sim \mathcal{N}\left(0, \sigma_{A}^{2}\right)$.

Firms post vacancies to employ new workers and they pay workers a real wage $w_{t}$. The firm's maximization problem yields the job creation condition:

$$
\frac{\kappa v_{t}^{\varphi-1}}{q\left(\theta_{t}\right)}=\beta \mathbb{E}_{t}\left[\left(1-S_{t+1}\right)\left(A_{t+1}-w_{t+1}+\frac{\kappa v_{t+1}^{\varphi-1}}{q\left(\theta_{t+1}\right)}\right)\right]
$$




\subsection{Wage Determination}

To close the model, wages are determined by Nash bargaining between a firm and a worker, where the worker has bargaining power $\eta \in(0,1)$. The sharing rule is given by:

$(1-\eta)\left(W_{t}-U_{t}\right)=\eta J_{t}$

where $W_{t}$ is the value of being employed, $U_{t}$ is the value of being unemployed, and $J_{t}$ is the value of a marginal worker to the firm. The value function equations are given in Appendix 2.

Substituting the value functions into the wage sharing rule (8) results in the following wage equation:

$w_{t}=\eta\left(A_{t}+\theta_{t} \kappa\right)+(1-\eta) b$.

Finally, substituting the wage equation (9) into the previously obtained job creation condition (7) results in an alternative representation of the job creation condition:

$\frac{\kappa}{q\left(\theta_{t}\right)}=\beta \mathbb{E}_{t}\left(1-s_{t+1}\right)\left[(1-\eta)\left(A_{t+1}-b\right)-\eta \theta_{t+1} \kappa+\frac{\kappa}{q\left(\theta_{t+1}\right)}\right]$.

\section{Estimation and Results}

Bayesian estimation is completed in three steps. First, we need to set prior values for the parameters of the model. Second, we log-linearize the model around a deterministic steady state and solve it. Third, we apply the Kalman filter to evaluate the likelihood function of the observables. The prior distribution of the parameters, together with the likelihood function forms the posterior distribution, where the posterior kernel is obtained through numerical simulation using the Metropolis-Hastings algorithm. 
Since the model has only two sources of uncertainty, the separation and productivity shock, only two sets of observables can be used. Due to this reason, this paper uses observations on the central variables in the model, unemployment and vacancies, for the benchmark specification observations.

\subsection{Prior Distribution}

The data sample covers the 2012Q1-2020Q1 period. The data are obtained from the Eurostat and the Croatian Bureau of Statistics databases and are seasonally adjusted and de-trended, as explained previously in Section 3.

Since this is one of the first empirical analyses of a search and matching model for the Croatian labor market that uses Bayesian estimation, most prior beliefs cannot be obtained from existing literature.

The model consists of seven structural parameters and five shock parameters. The discount rate is set to $\beta=0.98$ since the annual interest rate over the given period is approximately 7 percent. The prior of the elasticity of the matching function is determined by equating the flow into unemployment with the flow out of it: $m(u, v)=s(1-u)$ as done in Mortensen and Nagypal (2007). Thus, it is set to $\alpha=0.75$ with a standard deviation of 0.15 , which is just slightly out of the range of $(0.5,0.7)$ proposed by Petrongolo and Pissarides (2001).

The prior of the matching efficiency is determined to be consistent with the average observed job finding rate of 0.14 and set to $m_{0}=0.71$. The value of $m_{0}$ appears slightly larger than in other research. Most of the previous research has focused on OECD countries, although research by Šergo et al. (2009) shows that there has been an increase in the matching efficiency on the Croatian labor market since the 1990s, and thus the prior of the matching efficiency will be set to 0.71 . The prior mean of the job separation rate is set to the average value of $s=0.017$, which is lower than the values in the literature. The job separation rate is usually calibrated in the range of $(0.05,0.1)$. A possible explanation for such a 
low separation rate value is the strong employment protection policy present on the Croatian labor market, which does not allow for simple employment contract termination, as is discussed in Section 3.

Table 2: Prior Distributions of Parameters

\begin{tabular}{|c|c|c|c|c|}
\hline \multirow{2}{*}{ Description } & \multirow{2}{*}{ Parameter } & \multirow{2}{*}{ Density } & \multicolumn{2}{|c|}{ Prior } \\
\hline & & & Mean & Std. dev. \\
\hline Discount rate & $\beta$ & Fixed & 0.98 & - \\
\hline Match elasticity & $\alpha$ & Beta & 0.75 & 0.15 \\
\hline Match efficiency & $m_{0}$ & Gamma & 0.71 & 0.05 \\
\hline Separation rate & $s$ & Beta & 0.017 & 0.01 \\
\hline Unemployment benefit & $b$ & Beta & 0.7 & 0.1 \\
\hline Scaling factor on vacancy creation & $\kappa$ & Gamma & 2.12 & 0.1 \\
\hline Worker's bargaining power & $\eta$ & Uniform & 0.5 & 0.25 \\
\hline Elasticity of vacancy creation & $\varphi$ & Gamma & 1 & 0.5 \\
\hline AR-coefficient of shock process $A$ & $\rho_{A}$ & Beta & 0.5 & 0.25 \\
\hline AR-coefficient of shock process $s$ & $\rho_{s}$ & Beta & 0.5 & 0.25 \\
\hline Std. dev. of shock process $A$ & $\sigma_{A}$ & Inv. gamma & 0.01 & 1 \\
\hline Std. dev. of shock process $s$ & $\sigma_{s}$ & Inv. gamma & 0.01 & 1 \\
\hline Correlation between shocks & $\rho_{A, s}$ & Uniform & 0.5 & 0.29 \\
\hline
\end{tabular}

Note: Gamma distribution is used for real-valued parameters, inverse gamma distribution for standard deviations of shocks, and beta distribution for parameters with values on $(0,1)$.

Source: Author's calculations.

There are two options how to set the prior for unemployment benefits. The first one is to set it to the average value of replacement rates during the period, as in Martin (1998). The other option is to set it to a much lower value of 0.2 , as in Obadić (2003). For the baseline case, this paper uses the higher value of 0.7. Detailed results for the second case are given in Appendix 4.

The steady-state unemployment rate is treated as a target value for the empirical analysis, and by normalizing the mean productivity $A=1$, it can be seen from the steady job creation condition that $b$ and $\kappa$ cannot be separately identified. Thus, $\kappa$ is set to 2.12 . The elasticity of vacancy creation $\varphi$ is set to 1 . 
The bargaining power parameter is usually chosen to either be uniform on $(0,1)$ or to be equal to the match elasticity to satisfy the Hosios condition. Since we are interested in how much information on $\eta$ can be obtained from the data, $\eta$ is set to have a uniform prior over $(0,1)$.

Prior values of the autoregressive coefficients are chosen to have a degree of autocorrelation of 0.5 with wide standard errors for both shocks. Although previous research suggests that two shocks are most often negatively correlated, the data show positive correlation, resulting in a positive prior assumption of the correlation between shocks with a mean of 0.5 .

As is commonly used in Bayesian estimation, gamma distribution is used for realvalued parameters, inverse gamma distribution for standard deviations of shocks, and beta distribution for parameters with values on $(0,1)$. The prior values are summarized in Table 2.

\subsection{Posterior Distribution}

The model is estimated using the Kalman filter that constructs the likelihood function. The likelihood function is used to update the prior beliefs by applying Bayes' law. Table 3 contains parameter posterior means with their 90 percent confidence intervals. Figure 2 shows the prior and posterior distribution of parameters, as well as the mode values.

Most of the parameter means and distributions moved notably from their priors, resulting in a conclusion that the data are informative about the parameter values. Looking at match elasticity, the posterior mean moved considerably from the prior to 0.62 , which is in the range of $(0.5,0.7)$ proposed by Petrongolo and Pissarides (2001). The posterior mean of the separation rate moved from 0.017 to 0.038 . The posterior means and modes of the shock processes shifted notably. 


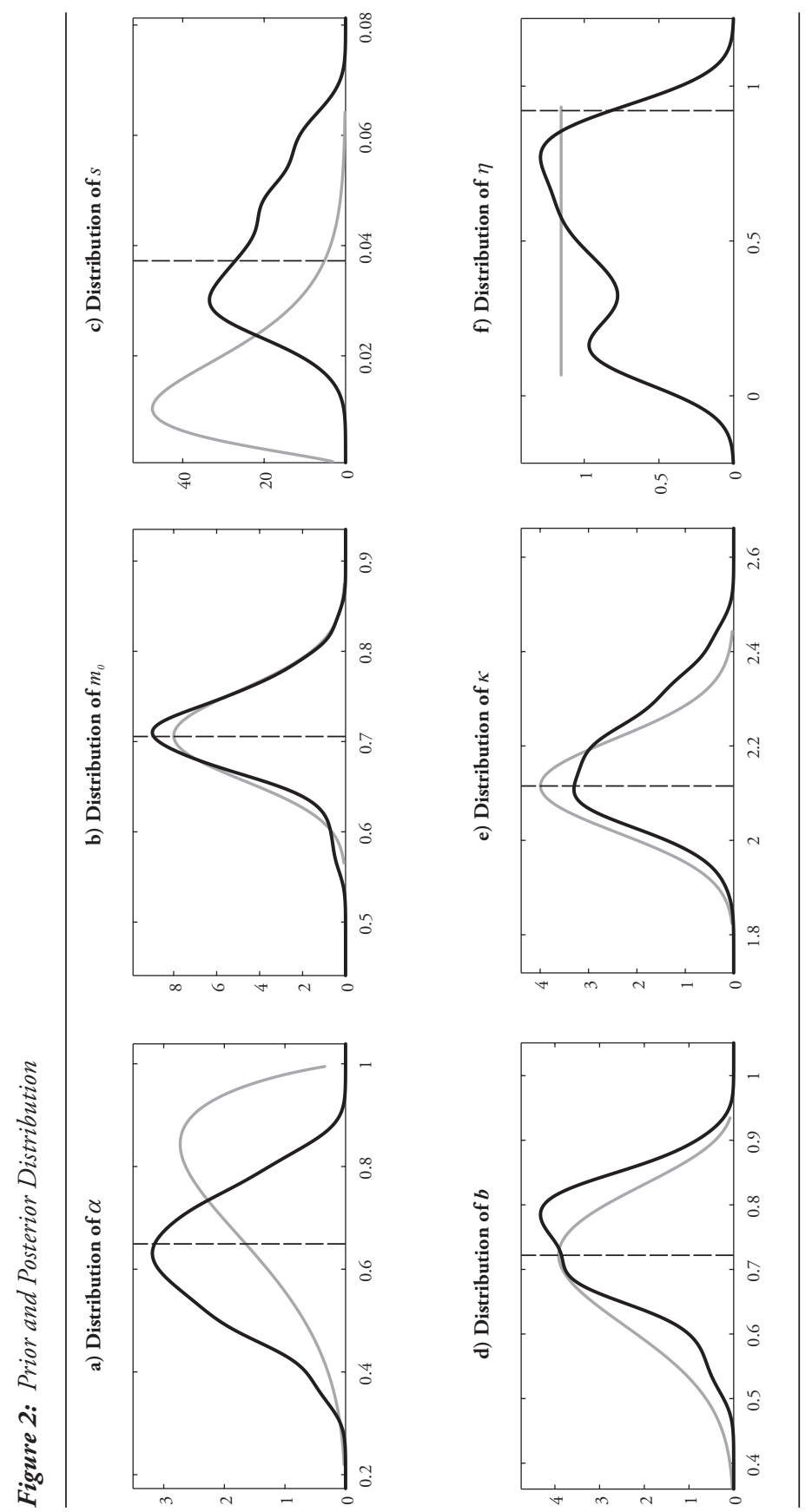



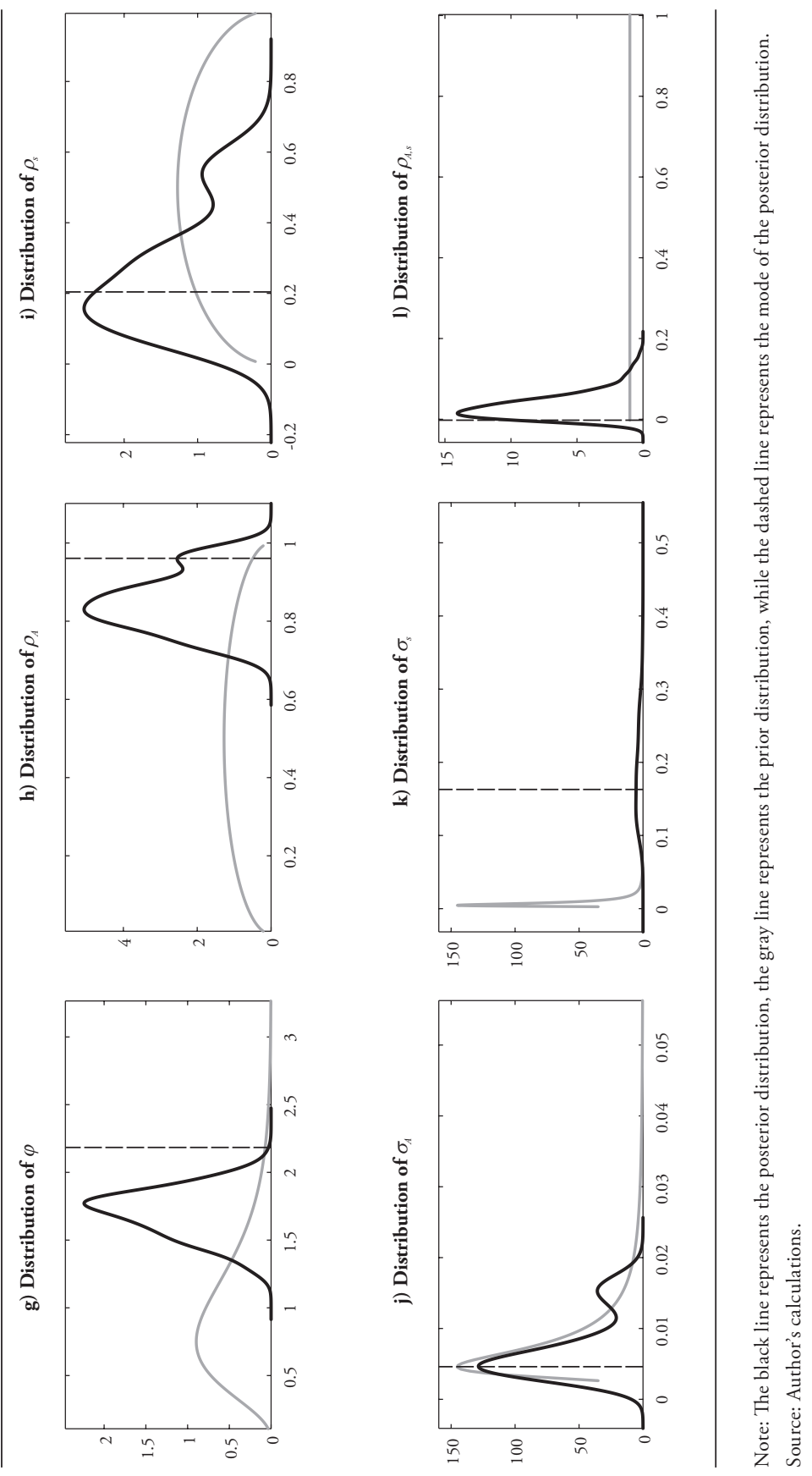
Table 3: Posterior Distributions of Parameters $(b=0.7)$

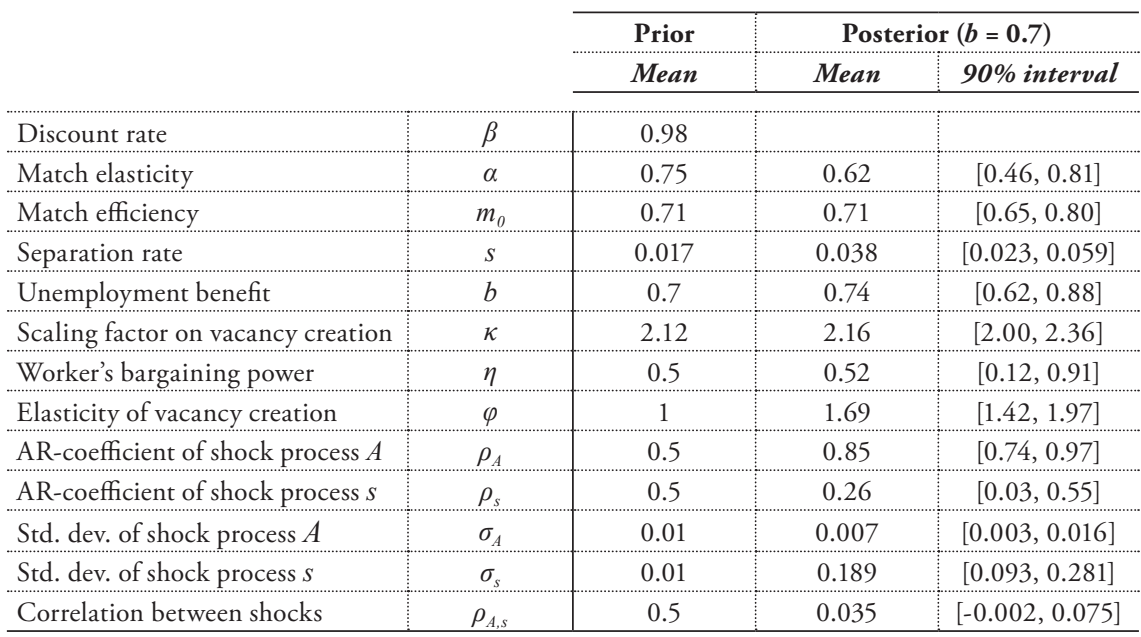

Source: Author's calculations.

The posterior distributions of the match efficiency, worker's bargaining power, and unemployment benefits moved away from their prior distributions, but to a smaller degree. The scaling factor on vacancy creation $\kappa$ did not move significantly from the prior, indicating that it is not identified. The finding that $\kappa$ is not identified is similar in most of the literature and is one of the reasons why it is often calibrated to a fixed number.

\subsection{Variance Decompositions}

To understand the sources of business cycles, Table 4 presents variance decompositions. In the baseline case, described in the first column, the productivity shock accounts for almost 98 percent of vacancy fluctuations and almost 85 percent of output fluctuations, while the separation shock plays a minor, but still important role. Looking at unemployment fluctuations, the ratio is rather different. Both the productivity and the separation shock play an important role in explaining unemployment fluctuations on the labor market in 
Croatia (approximately 55 percent and 45 percent, respectively), indicating that unemployment rate fluctuations are more sensitive to separation shocks compared to other variables. The same conclusion is reached when using a lower value for unemployment benefits, as shown in Appendix 4.

Table 4: Variance Decomposition

\begin{tabular}{c|c:c:c:c} 
& Baseline $[\boldsymbol{A}, \boldsymbol{s}]$ & $\boldsymbol{\varphi}=\mathbf{1}[\boldsymbol{A}, \boldsymbol{s}]$ & $\{\boldsymbol{v}, \boldsymbol{y}\}[\boldsymbol{A}, \boldsymbol{s}]$ & OVI $[\boldsymbol{A}, \boldsymbol{s}]$ \\
\cline { 2 - 5 } & {$[55.86,44.14]$} & {$[47.94,52.06]$} & {$[85.59,14.41]$} & {$[64.59,35.41]$} \\
\hline$v$ & {$[97.45,2.55]$} & {$[92.94,7.06]$} & {$[99.05,0.95]$} & {$[96.80,3.20]$} \\
\hline$y$ & {$[84.77,15.23]$} & {$[95.50,4.50]$} & {$[96.28,3.72]$} & {$[87.49,12.51]$} \\
\hline
\end{tabular}

Source: Author's calculations.

\subsection{Impulse Response Functions}

Impulse response functions are used to study the interactions between the variables of the model. They show the reactions of the variables to different shocks that hit the system. Figure 3 depicts the impulse response functions of the unemployment and vacancy rate to a one standard deviation positive shock to the separation rate and labor productivity. The impulse responses are derived at the posterior means of the parameters.

The first row of Figure 3 describes the impulse responses of unemployment and vacancies to positive shocks to the separation rate. On impact, the unemployment rate soars and then decreases in the following periods, vanishing to zero in the long run. An increase in unemployed workers results in an increase in the number of job seekers, and thus, firms have higher incentives to open new vacancies. This results in an almost instantaneous increase in vacancies at the time of impact of the shock, followed by a decrease, as seen in the case of unemployment.

The second row of Figure 3 describes the impulse responses of the two variables to a positive labor productivity shock. The unemployment rate slightly increases on impact, decreasing in the following periods, while the vacancy rate increases on impact and then gradually decreases over time. Since higher productivity 
levels of workers yield higher expected returns of hiring workers, firms open more vacancies, resulting in a decrease in unemployment.

Figure 3: Impulse Response Functions

a) Unemployment rate IRF to one s.d. separation shock

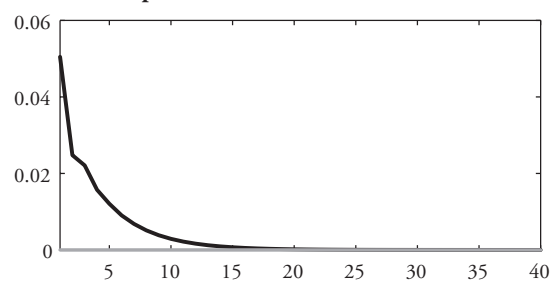

c) Unemployment rate IRF to one s.d. productivity shock

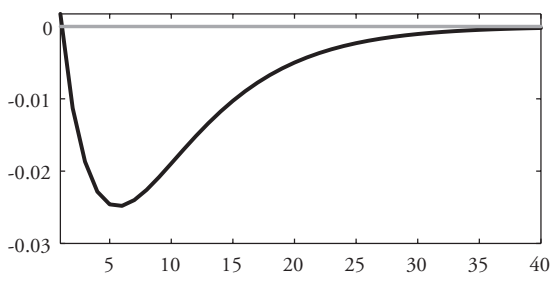

b) Vacancy rate IRF to one s.d. separation shock

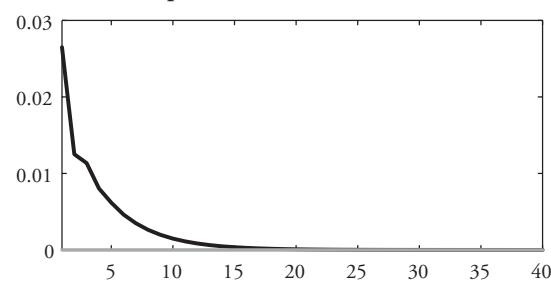

d) Vacancy rate IRF to one s.d. productivity shock

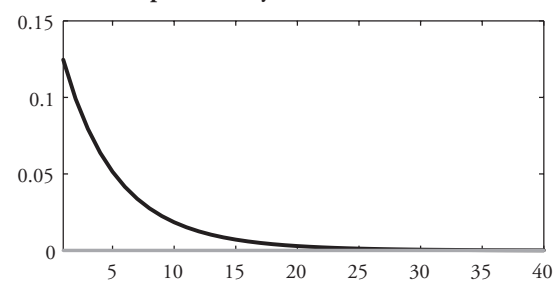

Notes: Impulse response functions of the unemployment and vacancy rate to a one standard deviation positive shock to the separation rate and labor productivity. The impulse responses are derived at the posterior means of the parameters.

Source: Author's calculations.

\subsection{Quantitative Performance of the Benchmark Model}

This section assesses the ability of the model to replicate the observed dynamics of the labor market. To do so, we need to compare the results of the simulations of the model when parameters are set to their posterior mean values with the actual data.

Simulation results and their data counterparts are shown in Table 5. The first column describes the data, while the second column presents the important statistics of the baseline case of the model. In the data, the standard deviations of unemployment and vacancy rates are close to 0.08 and 0.13 , respectively. In 
the baseline simulation, the model accounts for the volatility of the two variables, with the corresponding values being 0.10 and 0.21 , respectively. Furthermore, the model can account for the volatility of output as well.

The model can successfully replicate the negative relationship between unemployment and vacancies. The correlation between the unemployment and vacancy rate in the baseline simulation is -0.34 , while the correlation in the data is equal to -0.30 . With this, we can conclude that the baseline model provides us with a similar downward-sloping Beveridge curve as in the data.

Table 5: Model Fit

\begin{tabular}{l|c|c:c|c|c} 
& Data & Baseline & $\boldsymbol{\varphi}=\mathbf{1}$ & $\{\boldsymbol{v}, \boldsymbol{y}\}$ & OVI \\
\cline { 2 - 5 } Marginal likelihood & & 65.47 & 62.45 & & 74.42 \\
\hdashline$\sigma(u)$ & 0.076 & 0.098 & 0.089 & 0.067 & 0.094 \\
\hline$\sigma(v)$ & 0.132 & 0.211 & 0.248 & 0.157 & 0.135 \\
\hline$\sigma(y)$ & 0.012 & 0.025 & 0.045 & 0.019 & 0.024 \\
\hline$\sigma(s)$ & 0.316 & 0.196 & 0.237 & 0.111 & 0.143 \\
\hline$\sigma(A)$ & 0.013 & 0.014 & 0.036 & 0.012 & 0.012 \\
\hline$\rho(u, v)$ & -0.301 & -0.345 & -0.320 & -0.495 & -0.393 \\
\hline$\rho(s, A)$ & 0.147 & 0.015 & 0.011 & 0.116 & 0.019 \\
\hline$\sigma(u) / \sigma(y)$ & 6.33 & 3.92 & 1.97 & 3.52 & 3.92 \\
\hline$\sigma(v) / \sigma(y)$ & 11.00 & 8.44 & 5.43 & 8.26 & 5.62 \\
\hline
\end{tabular}

Source: Author's calculations.

Looking at the shock processes, on one hand, we can see that the model accounts for the observed volatility. On the other hand, the estimated baseline model is unable to replicate the correlation between the two processes. While the correlation between the separation process and the productivity process is positive in the data and in the baseline simulation, the data show ten times stronger correlation than the model.

To evaluate the quantitative performance of the model, it is important to observe the relative standard deviations of unemployment and vacancies to output. The relative standard deviation of unemployment to output equals 6.33 in the data, 
while it is smaller in the baseline estimation, with the value being 3.92. The relative standard deviation of vacancies to output with the values given by the data and the model are 11 and 8.44, respectively. The difference in values indicates that the Shimer puzzle is slightly present, as the volatility of the unemployment rate relative to the volatility of output given by the model is smaller in comparison to the relative standard deviation in the data, but overall, the results are satisfactory.

\subsubsection{Linear Vacancy Posting Costs}

Instead of a convex vacancy posting cost, it is common in the literature to incorporate a linear vacancy posting cost, and thus $\varphi$ is set to $\varphi=1$ and the model is once again estimated. The results are reported in the second column of Table 4, third column of Table 5 , and second column of Table 6.

Since the baseline case and the case with linear vacancy posting costs use the same set of observable variables, it is possible to compare the fit of the models by comparing the values of marginal likelihood. As can be seen in Table 5, the baseline model is slightly preferred to the model with linear vacancy posting costs, with the marginal likelihood of 65.47 compared to the marginal likelihood of 62.45 of the linear vacancy posting cost model.

The standard deviations of most variables are close in value to the benchmark case. The biggest differences can be seen in the standard deviations of output and productivity, as well as the relative standard deviations of unemployment and vacancies to output, although, overall, we can conclude that even with linear vacancy posting costs, the model performs well.

The posterior means of the parameters are close to the baseline estimates. Looking at column 2 of Table 6 , we can see that most of the values are similar to the baseline case. The biggest differences can be observed for match efficiency (0.72) and the bargaining coefficient (0.27). 
Table 6: Posterior Means of Estimated Parameters

\begin{tabular}{|c|c|c|c|c|}
\hline Parameter & Baseline & $\varphi=1$ & $\{v, y\}$ & OVI \\
\hline$\alpha$ & 0.62 & 0.72 & 0.58 & 0.49 \\
\hline$m_{0}$ & 0.70 & 0.71 & 0.71 & 0.71 \\
\hline$s$ & 0.038 & 0.031 & 0.027 & 0.047 \\
\hline$b$ & 0.74 & 0.70 & 0.70 & 0.69 \\
\hline$\kappa$ & 2.16 & 2.12 & 2.11 & 1.91 \\
\hline$\eta$ & 0.52 & 0.27 & 0.42 & 0.72 \\
\hline$\varphi$ & 1.69 & - & 1.48 & 1.86 \\
\hline$\rho_{A}$ & 0.85 & 0.94 & 0.93 & 0.76 \\
\hline$\rho_{s}$ & 0.26 & 0.25 & 0.30 & 0.28 \\
\hline$\sigma_{A}$ & 0.007 & 0.013 & 0.005 & 0.006 \\
\hline$\sigma_{s}$ & 0.189 & 0.229 & 0.105 & 0.137 \\
\hline$\rho_{A, s}$ & 0.035 & 0.038 & 0.420 & 0.050 \\
\hline
\end{tabular}

Source: Author's calculations.

Finally, looking at column 2 of Table 4, we can determine the sources of business cycle fluctuations. As in the baseline case, around 50 percent of unemployment fluctuations can be explained by separation shocks. Vacancy and output fluctuations are mainly caused by productivity shocks ( 93 percent and 95 percent, respectively) as in the baseline case, but with some differences, mainly in the case of output fluctuations.

\subsubsection{Estimation with Different Observable Variables}

In this section, we wish to see whether the model can generate an appropriate level of relative volatility between the observables if the set of observables changes. We are interested in seeing whether excluding the unemployment rate from the set of observables will give similar results as the baseline case. Thus, instead of observing the unemployment and vacancy rate, we observe the vacancy rate and output. 
Looking at the third column of Table 4, we can see that the dynamics of the model are mainly driven by the productivity process, especially in the case of vacancies and output (99 percent and 96 percent, respectively). The unemployment rate variation is also mainly generated by the productivity process, but the separation process has a strong effect as well. Although the influence of the separation process is smaller than in the baseline case, it still confirms the fact that unemployment variation, compared to vacancy and output variation, is heavily influenced by the separation process as well.

The estimated parameter values, presented in column 3 of Table 6 , are close to their baseline counterparts, with the largest difference being in the correlation between the shock processes. Furthermore, looking at column 4 of Table 5, we can see that most of the parameter estimates are rather close to the baseline estimates as well as their data counterparts, and the model fits the data well except in two cases. The standard deviation of the separation process is smaller than in both data and the baseline case, and the negative correlation between unemployment and vacancies is overestimated and equals -0.49 , compared to -0.3 in the data.

We can conclude that, overall, the model is able to perform well with a different set of observables. There are differences in the variance decomposition, but the main conclusion remains the same: the main driving force of fluctuations for all three variables is the productivity process, while the separation process has an important role in explaining unemployment variation.

\subsubsection{Online Vacancy Index}

Unlike the rest of the paper that uses vacancy rate data, this section will use the Online Vacancy Index (OVI $)^{4}$ instead of the vacancy rate. The results are reported in the last column of Table 4, Table 5, and Table 6.

4 The OVI index is developed by means of simple enumeration of single new job advertisements whose application deadlines end within the same month for which the index is being calculated. Given that advertisements published by only one web portal are taken into account, the number of job advertisements is expressed as an index (with the base year being 2015). 
Looking at the variance decomposition given in Table 4, we can see that, as in the baseline case, the productivity shock accounts for most of the vacancy volatility, as well as output volatility, 97 percent and 87 percent, respectively. In explaining unemployment volatility, both the productivity and separation process are important factors, the separation rate accounting for 35 percent of unemployment fluctuations.

The posterior means of the parameters, shown in the final column of Table 6 , have similar values as in the baseline case, with two major differences: the match elasticity is estimated to be significantly lower, while the bargaining parameter has a higher value opposed to the baseline.

The model performs well, as can be seen in the last column of Table 5. The standard deviations of the variables are close to their data counterparts, except for the separation rate. The correlation between unemployment and vacancies is slightly overestimated and equals -0.39 . Finally, the relative standard deviations of unemployment and vacancies to output are still lower compared to their data counterparts, but overall, we can conclude that the model performs well with different vacancy data.

\section{Conclusion}

The focus of this paper is to see to what extent a simple search and matching model can describe the dynamics of the labor market in Croatia. Most research related to search and matching models focuses on the labor markets of OECD countries. As developing (or recently developed) economies differ from developed ones, it is important to determine the driving forces behind fluctuations on the labor markets in these countries.

The model developed in this paper is a discrete-time search and matching model with convex vacancy posting costs and two types of shock processes: productivity and separation shocks. After determining prior values for the parameters of the 
model, the paper uses Bayesian estimation to obtain the posterior values for the model parameters.

The model can describe the aggregate labor market dynamics in Croatia well. It can replicate the observed volatility of the variables, as well as the negative correlation between the unemployment and vacancy rate. The model is, however, unable to replicate the extent of the positive relationship between the shock processes. Overall, it can be concluded that the baseline model is good at replicating the dynamics of the Croatian labor market.

The results show that the productivity shock accounts for most of the vacancy and output fluctuations, while the separation shock plays a minor role. In the case of unemployment fluctuations, both shock processes are almost equally important in explaining unemployment fluctuations. The same conclusion is reached even when using a lower value for unemployment benefits: the separation shock has a strong effect on the unemployment dynamics in Croatia. This finding has important implications in policy formation.

Introducing linear vacancy posting costs instead of convex ones slightly diminishes the ability of the model to replicate the dynamics of the labor market, although the model still performs well. Changing the set of observable variables, we can conclude that the model is a good fit for the labor market, as the conclusion mainly remains the same. The model can generate an appropriate level of relative volatility between the observables if the set of observables changes. Furthermore, using different data on vacancies, the model performs well and once again the model shows that the separation shock heavily influences the unemployment dynamics in Croatia.

To be able to describe the labor market in Croatia even better, a longer data span as well as data on wages are necessary. Additionally, introducing another shock process may improve the ability of the model to replicate the aggregate dynamics of the labor market. This remains to be done in future research. 


\section{Appendix 1: Details about Derivation of Equation 7}

The firm chooses its optimal employment level and number of vacancies to post by maximizing the inter-temporal profit function:

$\mathbb{E} \sum_{t=0}^{\infty} \beta^{t}\left(A_{t} n_{t}-w_{t} n_{t}-\kappa v_{t}^{\varphi} / \varphi\right)$

subject to the employment evolution equation (4). The first-order conditions are given by the following equations:

$$
\begin{aligned}
& {\left[n_{t}\right]: \mu_{t}=A_{t}-w_{t}+\beta \mathbb{E}_{t}\left[\mu_{t+1}\left(1-s_{t+1}\right)\right]} \\
& {\left[v_{t}\right]: \kappa v_{t}^{\varphi-1}=\beta q\left(\theta_{t}\right) \mathbb{E}_{t}\left[\mu_{t+1}\left(1-s_{t+1}\right)\right],}
\end{aligned}
$$

where $\mu_{t}$ is the Lagrange multiplier on the employment equation. Combining these two conditions gives the job creation condition:

$$
\frac{\kappa v_{t}^{\varphi-1}}{q\left(\theta_{t}\right)}=\beta \mathbb{E}_{t}\left[\left(1-S_{t+1}\right)\left(A_{t+1}-w_{t+1}+\frac{\kappa v_{t+1}^{\varphi-1}}{q\left(\theta_{t+1}\right)}\right)\right] \text {. }
$$

\section{Appendix 2: Value Functions}

The value of being employed is given by the following Bellman equation:

$$
W_{t}=w_{t}+\beta \mathbb{E}_{t}\left[\left(1-S_{t+1}\right) W_{t+1}+S_{t+1} U_{t+1}\right] \text {. }
$$

Equation (A1) states that an employed worker receives a wage in the current period and with probability $s_{t+1}$ becomes unemployed in the next period, and with probability $1-s_{t+1}$ remains employed in the next period.

The value of being unemployed is given by the following Bellman equation:

$$
U_{t}=b+\beta \mathbb{E}_{t}\left[\theta_{t} q\left(\theta_{t}\right)\left(1-s_{t+1}\right) W_{t+1}+\left(1-\theta_{t} q\left(\theta_{t}\right)\left(1-s_{t+1}\right)\right) U_{t+1}\right],
$$

where $b$ stands for unemployment benefits that an unemployed worker receives. 
The value of the marginal worker to the firm is equal to the Lagrange multiplier on the employment constraint (4), resulting in:

$J_{t}=A_{t}-w_{t}+\beta \mathbb{E}_{t}\left[J_{t+1}\left(1-s_{t+1}\right)\right]$.

\section{Appendix 3: Dynamics of the Model}

The dynamics of the model are given by equations (2), (4), and (10), and the definition of labor market tightness $\theta$, with shock processes (3) and (6) as driving processes.

$n_{t}=1-u_{t}$

$n_{t}=\left(1-s_{t}\right)\left(n_{t-1}+m_{0} u_{t-1}^{\alpha} v_{t-1}^{1-\alpha}\right)$.

$\frac{\kappa}{q\left(\theta_{t}\right)}=\beta \mathbb{E}_{t}\left(1-s_{t+1}\right)\left[(1-\eta)\left(A_{t+1}-b\right)-\eta \theta_{t+1} \kappa+\frac{\kappa}{q\left(\theta_{t+1}\right)}\right]$.

$\theta_{t} \equiv v_{t} / u_{t}$

$\log s_{t}=\left(1-\rho_{s}\right) \log s-\rho_{s} \log s_{t-1}+\epsilon_{s, t}$,

where $0<\rho_{s}<1,0<s<1$, and $\epsilon_{s, t} \sim \mathcal{N}\left(0, \sigma_{s}^{2}\right)$.

$\log A_{t}=\left(1-\rho_{A}\right) \log A-\rho_{A} \log A_{t-1}+\epsilon_{A, t}$,

where $0<\rho_{A}<1,0<A<1$, and $\epsilon_{A, t} \sim \mathcal{N}\left(0, \sigma_{A}^{2}\right)$. 


\section{Appendix 4: Lower Value of Unemployment Benefits $(b=0.2)$}

Table A1: Posterior Distributions of Parameters $(b=0.2)$

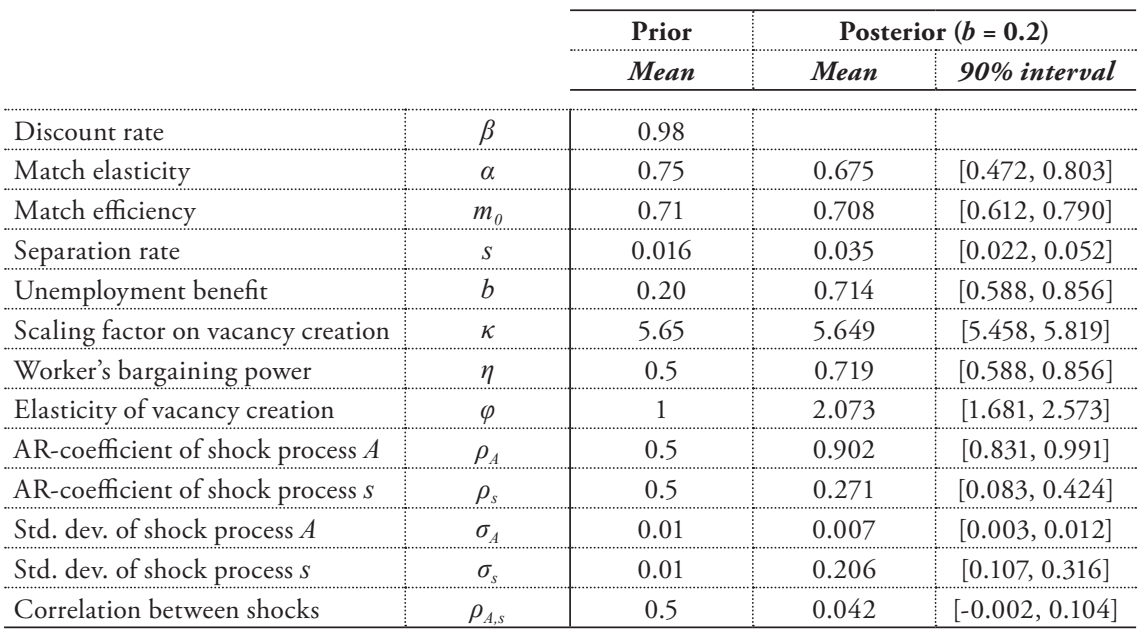

Source: Author's calculations.

Table A2: Variance Decomposition $(b=0.2)$

\begin{tabular}{c|c|c|c}
\cline { 2 - 3 } \multicolumn{2}{c|}{ Baseline $(\boldsymbol{b}=\mathbf{0 . 2})[\boldsymbol{A}, \boldsymbol{s}]$} & $\boldsymbol{\varphi}=\mathbf{1}[\boldsymbol{A}, \boldsymbol{s}]$ & $\{\boldsymbol{v}, \boldsymbol{y}\}[\boldsymbol{A}, \boldsymbol{s}]$ \\
\cline { 2 - 4 }$u$ & {$[54.65,45.35]$} & {$[40.77,59,23]$} & {$[100.00,0.00]$} \\
\hline$v$ & {$[98.53,1.47]$} & {$[88.44,11.56]$} & {$[0.05,99.95]$} \\
\hline$y$ & {$[87.60,12.40]$} & {$[99.26,0.74]$} & {$[77.81,22.19]$} \\
\hline
\end{tabular}

Source: Author's calculations. 
Table A3: Model Fit $(b=0.2)$

\begin{tabular}{|c|c|c|c|c|}
\hline & Data & Baseline & $\varphi=1$ & $\{v, y\}$ \\
\hline Marginal likelihood & & 65.07 & & \\
\hline$\sigma(u)$ & 0.076 & 0.099 & 0.092 & 0.063 \\
\hline$\sigma(v)$ & 0.132 & 0.238 & 0.212 & 0.096 \\
\hline$\sigma(y)$ & 0.012 & 0.028 & 0.124 & 0.020 \\
\hline$\sigma(s)$ & 0.316 & 0.215 & 0.255 & 0.405 \\
\hline$\sigma(A)$ & 0.013 & 0.017 & 0.116 & 0.017 \\
\hline$\rho(u, v)$ & -0.301 & -0.447 & -0.138 & 0.997 \\
\hline$\rho(s, A)$ & 0.147 & 0.014 & 0.013 & -0.001 \\
\hline$\sigma(u) / \sigma(y)$ & 6.33 & 3.48 & 0.74 & 3.15 \\
\hline$\sigma(v) / \sigma(y)$ & 11.00 & 8.38 & 1.71 & 4.80 \\
\hline
\end{tabular}

Source: Author's calculations.

Table A4: Posterior Means of Estimated Parameters $(b=0.2)$

\begin{tabular}{|c|c|c|c|}
\hline Parameter & Baseline & $\varphi=1$ & $\{v, y\}$ \\
\hline$\alpha$ & 0.67 & 0.67 & 0.75 \\
\hline$m_{0}$ & 0.71 & 0.72 & 0.71 \\
\hline$s$ & 0.035 & 0.030 & 0.019 \\
\hline$b$ & 0.71 & 0.23 & 0.19 \\
\hline$\kappa$ & 5.65 & 5.65 & 5.66 \\
\hline$\eta$ & 0.72 & 0.41 & 0.62 \\
\hline$\varphi$ & 2.07 & - & 0.73 \\
\hline$\rho_{A}$ & 0.90 & 0.91 & 0.60 \\
\hline$\rho_{s}$ & 0.27 & 0.19 & 0.46 \\
\hline$\sigma_{A}$ & 0.007 & 0.048 & 0.014 \\
\hline$\sigma_{s}$ & 0.207 & 0.250 & 0.359 \\
\hline$\rho_{A, s}$ & 0.040 & 0.037 & -0.001 \\
\hline
\end{tabular}

Source: Author's calculations. 


\section{Literature}

Abeille-Becker, C., \& Clerc, P. (2013). The cyclical behavior of the unemployment, job finding and separation rates. Revue Economique, 64(3), 519-526. doi: https:// doi.org/10.3917/reco.643.0519

Botrić, V. (2009). Unemployed and long-term unemployed in Croatia: Evidence from Labour Force Survey. Revija za socijalnu politiku, 16(1), 25-44. doi: https:// doi.org/10.3935/rsp.v16i1.807

Brkić, M. (2015). Labor market duality and the impact of prolonged recession on employment in Croatia. Croatian Economic Survey, 17(1), 5-45.

Croatian Bureau of Statistics. (2020). Statistics in line. Retrieved from: www.dzs.hr

Croatian National Bank (CNB). (2010). Bulletin No. 160 - Quarterly report. Zagreb: Croatian National Bank.

Croatian National Bank (CNB). (2020). Main macroeconomic indicators. Retrieved from: https://www.hnb.hr/en/statistics/main-macroeconomic-indicators

Eurostat. (2020). Eurostat database. Retrieved from:

https://ec.europa.eu/eurostat/data/database

Franičević, V. (2011). Croatia: Prolonged crisis with an uncertain ending. In D. Vaughan-Whitehead (Ed.), Work inequalities in the crisis (pp. 143-197). Cheltenham: Edward Elgar Publishing.

Fujita, S., \& Ramey, G. (2007). Job matching and propagation. Journal of Economic Dynamics and Control, 31(11), 3671-3698.

doi: https://doi.org/10.1016/j.jedc.2006.12.008

Fujita, S., \& Ramey, G. (2012). Exogenous versus endogenous separation. American Economic Journal: Macroeconomics, 4(4), 68-93.

doi: https://doi.org/10.1257/mac.4.4.68

Hagedorn, M., \& Manovskii, I. (2008). The cyclical behavior of equilibrium unemployment and vacancies revisited. American Economic Review, 98(4), 16921706. doi: https://doi.org/10.1257/aer.98.4.1692 
Hall, R. E., \& Milgrom, P. R. (2008). The limited influence of unemployment on the wage bargain. American Economic Review, 98(4), 1653-1674.

doi: https://doi.org/10.1257/aer.98.4.1653

Lin, C. Y., \& Miyamoto, H. (2014). An estimated search and matching model of the Japanese labor market. Journal of the Japanese and International Economies, 32, 86-104. doi: https://doi.org/10.1016/j.jjie.2014.03.001

Lise, J., Seitz, S., \& Smith, J. A. (2005). Evaluating search and matching models using experimental data. IZA Discussion Paper No. 1717.

Lubik, T. A. (2012). Aggregate labour market dynamics in Hong Kong. Pacific Economic Review, 17(2), 257-279. doi: https://doi.org/10.1111/j.14680106.2012.00582.x

Martin, J. P. (1998). What works among active labour market policies: Evidence from OECD countries' experiences. OECD Labour Market and Social Policy Occasional Paper No. 35.

Menzio, G., \& Shi, S. (2011). Efficient search on the job and the business cycle. Journal of Political Economy, 119(3), 468-510.

doi: https://doi.org/10.1086/660864

Mortensen, D. T., \& Nagypal, E. (2007). More on unemployment and vacancy fluctuations. Review of Economic Dynamics, 10(3), 327-347.

doi: https://doi.org/10.1016/j.red.2007.01.004

Nikolic, J., Rubil, I., \& Tomić, I. (2017). Pre-crisis reforms, austerity measures and the public-private wage gap in two emerging economies. Economic Systems, 41(2), 248-265. doi: https://doi.org/10.1016/j.ecosys.2016.06.001

Obadić, A. (2003). Utjecaj aktivnih i pasivnih politika na tržište rada. Financijska teorija i praksa, 27(4), 529-546.

Obadić, A. (2004). Measuring labour market policies' efficiency in Croatia. Journal for Institutional Innovation, Development \& Transition, 8, 34-47.

Obadić, A. (2006). Theoretical and empirical framework of measuring mismatch on a labour market. Zbornik radova Ekonomskog fakulteta u Rijeci: ćasopis za ekonomsku teoriju i praksu, 24(1), 55-80. 
Obadić, A., \& Majić, E. (2013). Analiza strukture nezaposlenosti visokoobrazovanih osoba u Republici Hrvatskoj i mjere za njezino smanjivanje. Poslovna izvrsnost, 7(2), 103-122.

Orsini, K., \& Ostojić, V. (2015). Wage dynamics in Croatia: Leaders and followers. European Economy Economic Brief No. 003.

Petrongolo, B., \& Pissarides, C. A. (2001). Looking into the black box: A survey of the matching function. Journal of Economic Literature, 39(2), 390-431. doi: https://doi.org/10.1257/jel.39.2.390

Pissarides, C. A. (2000). Equilibrium unemployment theory. Cambridge, MA: MIT Press.

Robin, J. M. (2011). On the dynamics of unemployment and wage distributions. Econometrica, 79(5), 1327-1355. doi: https://doi.org/10.3982/ECTA9070

Rotemberg, J. J. (2006). Cyclical wages in a search-and-bargaining model with large firms. NBER Working Paper No. 12415.

doi: https://doi.org/10.3386/w12415

Šergo, Z., Poropat, A., \& Gržinić, J. (2009). Croatia’s Beveridge curve and estimation of natural rate of unemployment: 1990-2008. Economic ResearchEkonomska istraživanja, 22(3), 29-47.

Shimer, R. (2005). The cyclical behavior of equilibrium unemployment and vacancies. American Economic Review, 95(1), 25-49.

doi: https://doi.org/10.1257/0002828053828572

The Institute of Economics, Zagreb. (2020). Online vacancy index. Retrieved from: https://www.eizg.hr/

Tomić, I. (2014a). Structural unemployment in Croatia - How important is the occupational mismatch? Economic Research-Ekonomska istraživanja, 27(1), 346365. doi: https://doi.org/10.1080/1331677X.2014.966969

Tomić, I. (2014b). Regional matching (in)efficiency on the Croatian labour market. Acta Oeconomica, 64(3), 287-312.

doi: https://doi.org/10.1556/aoecon.64.2014.3.2

Tomić, I., \& Domadenik, P. (2012). Matching, adverse selection and labour market flows in a (post)transition setting: The case of Croatia. Post-Communist Economies, 24(1), 39-72. doi: https://doi.org/10.1080/14631377.2012.647969 
Tomić, I., Rubil, I., Nestić, D., \& Stubbs, P. (2019). The employment and social situation in Croatia. Luxembourg: European Parliament.

Tomić, I., \& Zilic, I. (2020). Working for 200 euro? The unintended effects of traineeship reform on youth labor market outcomes. Labour, 34(3), 347-371. doi: https://doi.org/10.1111/labr.12176

Weber, M. (2016). Wage determination and employment adjustment in Croatia. CESifo Forum, 17(1), 22-26.

World Bank. (2010). Social impact of the crisis and building resilience. World Bank Report No. 55111. 